\title{
CAO National Incident Reports
}

These graphs reflect information obtained from all national incident reports, to January 15, 2013. Over the past twelve months, 989 incident reports have been received. This report provides information on 1,121 incidents, whereas the report from January 2012 included 132 incidents. A detailed national report has been circulated to all provincial associations. In addition, a provincial report has also been provided to the provinces regarding incidents taking place in their provinces. The National Public Education Committee (NPEC) is asking for patient stories that would make an impact and resonate with general audiences. The provincial reports provide details of the type of incidents being reported and the examination details from each incident reported for that province. This will be a good source for stories to become part of the NPEC campaign.

The CAO has already used the incident report data as evidence in supporting advocacy positions. Optometrists must be diligent about taking the few minutes that are required to report incidents they see related to unregulated practices and specifically to asymptomatic patients, internet sales, sight testing and non-corrective contact lenses.

The following is information compiled from the incident reports.
National Incident Reports By Province

January $2013 \quad(n=1121)$

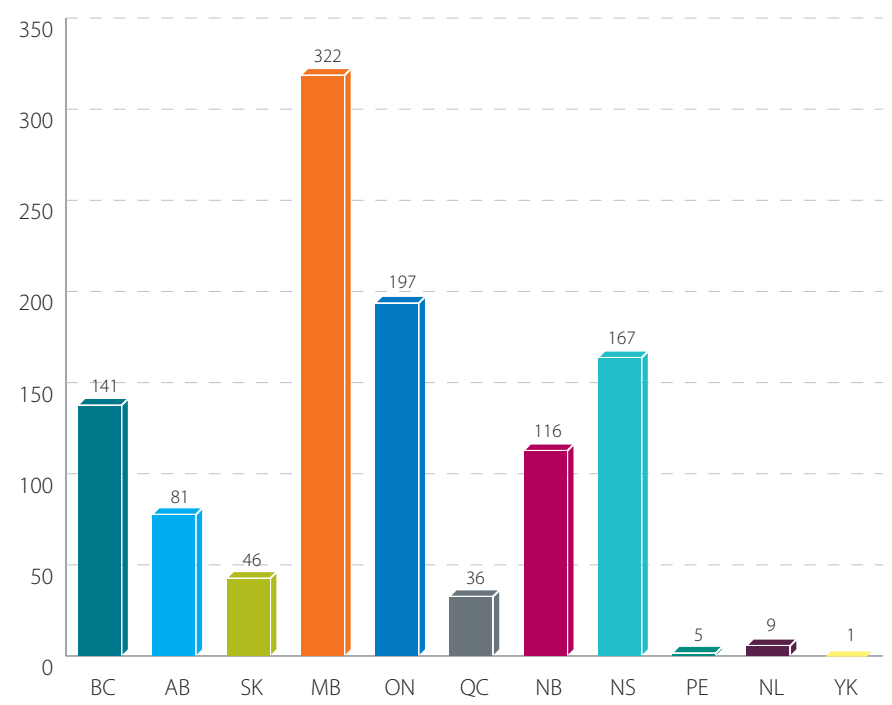

\section{Incident Reports by Type - \% of total reports}

January 2013 ( $n=1121)$

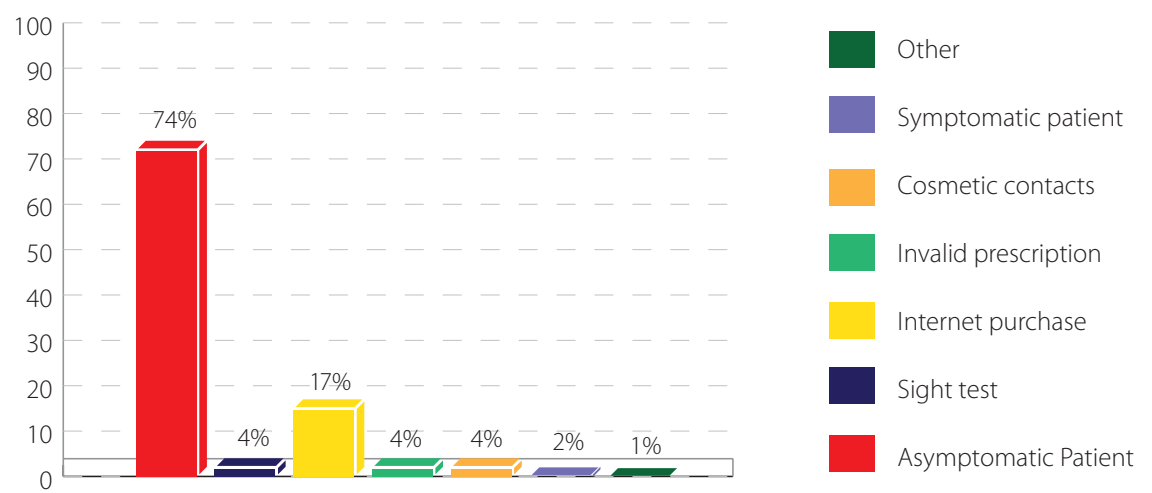

\section{Incident Reporting}

CAO reminds members to continue to report patient incidents on the national incident reporting site. Add to your provincial total by reporting asymptomatic patients, invalid prescriptions, online ordering, sight tests, and cosmetic contact lenses.

Please support this effort! To report an incident, visit: www.surveymonkey.com/s/ ODincidentreport

Déclaration des incidents L'ACO rappelle aux membres de continuer à déclarer les incidents liés à des patients sur le site national de déclaration des incidents. Contribuez aux totaux de votre province en déclarant les patients asymptomatiques, les prescriptions non valides, les commandes en ligne, les tests de la vue et les lentilles cornéennes à but esthétique.

Veuillez appuyer cet effort! Pour signaler un incident, rendez-vous à : http:// www.surveymonkey.com/s/ODrapportincident

On all graphs, the total percentage may be greater than one hundred, because more than one incident was identified per report. 
Initial Reason for Visiting OD

January 2013

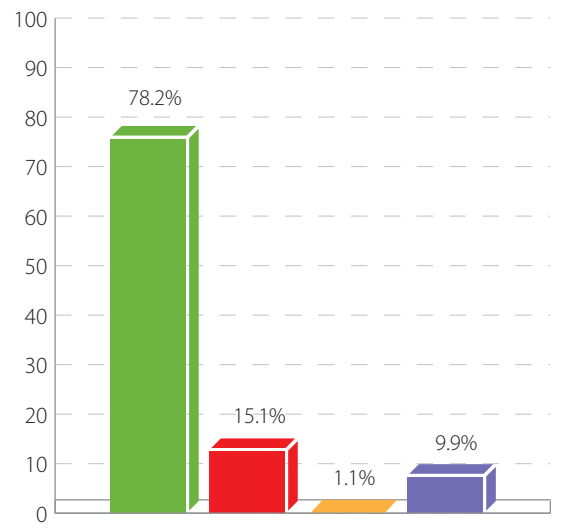

Incidents Reported by Age of Patients

January 2013

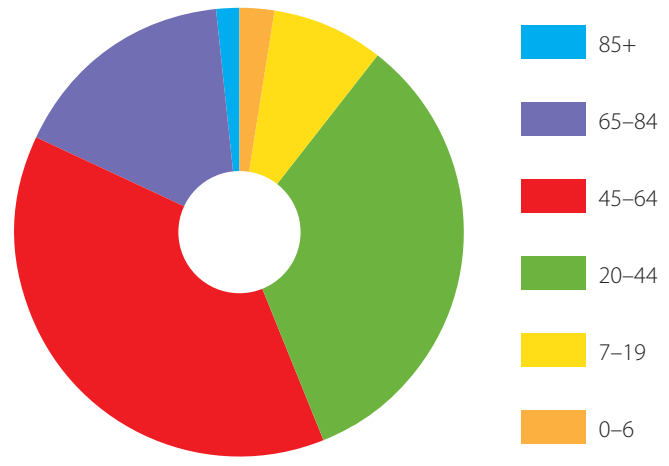

Patient Gender of Incidents Reported January 2013

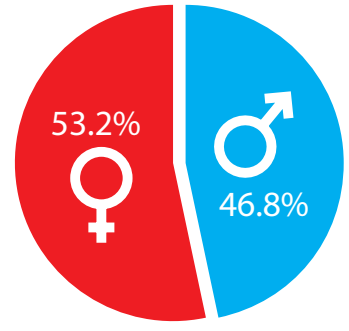

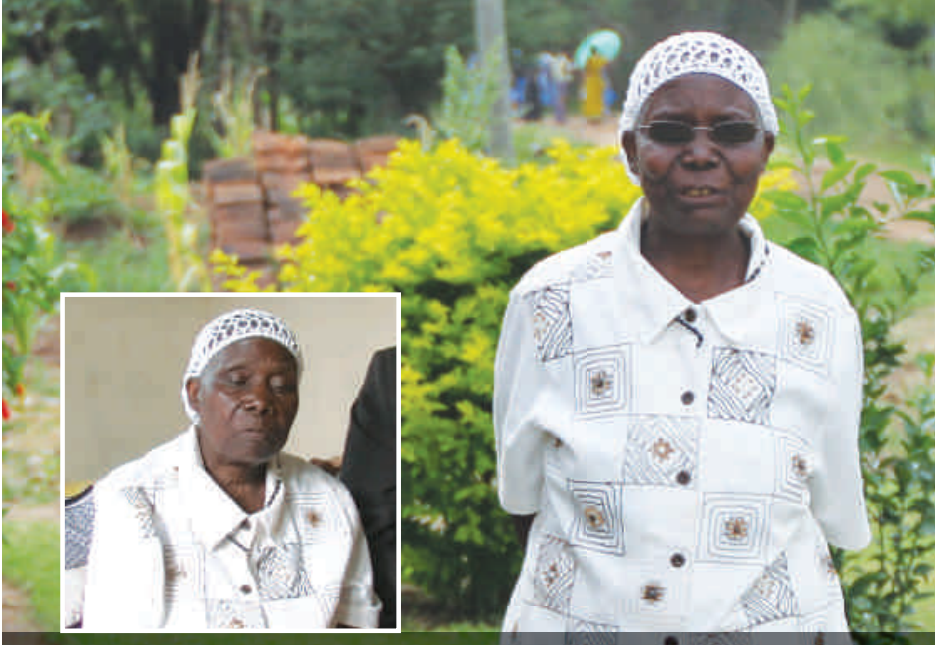

"I thought my life was ending because I could no longer see clearly

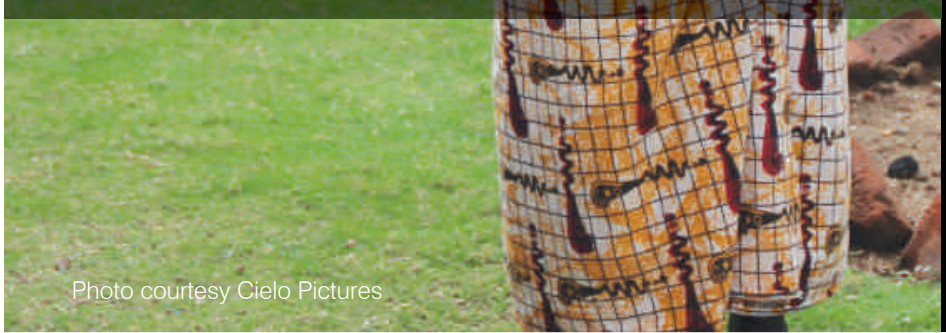

\section{"n now I feel reborn."}

Margareth: Tanzania, East Africa.

By funding the training of local optometrists and the establishment of local vision centres, Optometry Giving Sight is transforming the lives of millions in need. We urgently need your support to help more people like Margareth.

Please become a monthly donor today: www.givingsight.org or call 18005858265 ext 4

\section{OPTOMETRYGIVINGSIGHT} Transforming lives through the gift of vision

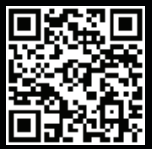

